\title{
Studies of Cellulose Acetate Supported Ergosterol Liquid Membrane
}

\section{Vandana Upadhyay*}

Department of Chemistry, Marwar Business School, Gorakhpur, Uttar Pradesh, India

\begin{abstract}
Supported liquid membrane on cellulose acetate matrix has been formed by using ergosterol, a fungal product as a surfactant. The behaviour of this membrane has been simulated with biological membranes by its electrochemical characterization. For this purpose membrane potential has been measured using $\mathrm{NaCl}$ and $\mathrm{CaCl}_{2}$ solutions of different concentrations. Ionic transport numbers have been used to estimate fixed charge density and permselectivity. The variation of membrane potential has also been examined as a function of concentration and $\mathrm{pH}$ values of $\mathrm{NaCl} \& \mathrm{CaCl}_{2}$ solutions.
\end{abstract}

Keywords: Ergosterol; Liquid membrane

\section{Introduction}

Liquid membrane technology has attracted attention recently because of its numerous applications which include gas transport, metal ion recovery, waste water treatment, reverse osmosis, desalination, biotechnology and biomedical engineering [1-6]. Liquid membranes are usually formed at every interface encountered by a surfactant solution. Permeation through liquids is orders of magnitude faster than that through solid polymers of comparable thickness. Among various studies on surfactant generated liquid membranes [7], the studies with surfactants of fungal origin are rare. Ergosterol is a fungal product and a biologically important material known as provitamin D which can be converted to vitamin D2 on exposure to ultraviolet radiation. The epidermal cells of the skin of man and animal contain large amount of ergosterol, which is converted to vit D2 by exposure of the skin to sunlight. Vitamin D2 is a powerful antirachitic compound for man and rat. It helps in maintaining the levels of calcium and phosphorus in the body and is involved in resorption of calcium from calcified bones by osteolytic cells. Vitamin D2 is necessary for proper growth of bone and teeth.

Ergosterol has therefore been used in the present investigation as a surfactant for the formation of liquid membrane supported on the cellulose acetate matrix. Ergosterol is a white crystalline compound. There is a hydroxyl group present in ergosterol. Three double bonds are also present in its nucleus. Ergosterol is non ionic as such. The liquid membrane has been electrochemically characterized by measuring membrane potentials by the use of $\mathrm{NaCl}$, and $\mathrm{CaCl}_{2}$ solutions of various concentrations. Structure of ergosterol is given in Figure 1.

\section{Materials and Methods}

The film of cellulose acetate was prepared as already reported [8]. The thickness of cellulose acetate film used was $7.3 \times 10^{-5} \mathrm{~m}$ and its cross sectional area was $1.78 \times 10^{-4} \mathrm{~m}^{2}$. Liquid membrane generation was accomplished $[9,10]$ following the method suggested by Gershfeld and Pagano [11] . A large amount of water was added to a known amount of ergosterol (ACROS ORGANICS) dissolved in ethanol. The mixture was constantly stirred. Dispersions of ergosterol of different known concentrations were thus prepared. Generation of liquid membrane was carried out by first equilibrating the film with water and then keeping it in contact with ergosterol solution of lowest concentration. To ascertain the minimum concentration needed for liquid membrane formation, Ergosterol suspension of different concentrations were prepared and used. The minimum ergosterol concentration needed

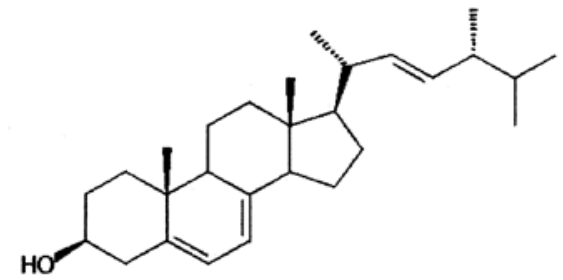

Figure 1: Ergosterol.

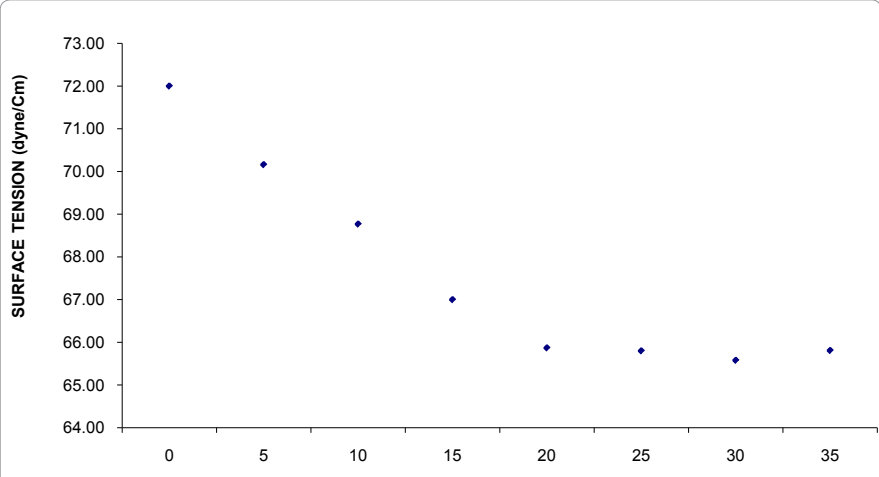

Figure 2: Critical Micelle Concentration Determination by Surface Tension Measurements.

for complete liquid membrane formation was found to be $20 \mu \mathrm{M}$. It is believed that liquid membrane formation occurs when the critical micelle concentration (CMC) is exceeded. The CMC was determined by measuring surface tension and it was found to be $20 \mu \mathrm{M}$. Membrane resistance was measured. Ergosterol dispersions of higher concentration $(35 \mu \mathrm{M})$ were used in the present study.

*Corresponding author: Vandana Upadhyay, Department of Chemistry, Marwar Business School, Gorakhpur, Uttar Pradesh, India, E-mail: vandana_gkp@yahoo.com

Received January 28, 2012; Accepted May 22, 2012; Published May 27, 2012

Citation: Upadhyay V (2012) Studies of Cellulose Acetate Supported Ergosterol Liquid Membrane. J Memb Sci Technol 2:116. doi:10.4172/2155-9589.1000116

Copyright: (c) 2012 Upadhyay V, et al. This is an open-access article distributed under the terms of the Creative Commons Attribution License, which permits unrestricted use, distribution, and reproduction in any medium, provided the original author and source are credited. 
Membrane potential was measured as usual [12] with the help of digital multimeter (MAS 830) using calomel electrodes. Sodium chloride and calcium chloride solutions of unequal concentrations with and without ergosterol were kept on either side of the supported matrix to allow equilibration and liquid membrane formation. Membrane potentials were also measured in the same manner using sodium chloride and calcium chloride solutions of different $\mathrm{pH}$ values.

\section{Results and Discussion}

The formation of liquid membrane was ascertained by measuring membrane resistance using ergosterol suspensions of different concentrations. Due to accumulation of ergosterol in the interfacial region, the resistivity changed and approached a constant value after 3-4 h. This was attributable to the accumulation of ergosterol in the interfacial region. The plot of surface tension against concentrations of ergosterol solutions is given in Figure 2. The trend shows that upto the CMC $(20 \mu \mathrm{M})$ of ergosterol and thereafter the values of surface tension become constant. This is in consonance with Kesting's hypothesis. With increasing concentration of ergosterol, the surface tension of water is lowered showing that the interface is being progressively covered. The critical micelle concentration must be exceeded for the occurrence of complete liquid membrane formation. Surface tension was also measured when the surfactant solution contained different concentrations of electrolytes ( $\mathrm{Nacl}$ and $\mathrm{Cacl} 2)$. The value of CMC in presence of all the electrolytes remains almost constant (Figure 3,4). A curve almost parallel to concentration axis ensures that the interface is completely covered. Membrane potential was measured using the following type of experimental cell:

$\begin{aligned} & \text { Reference Calomel } \\ & \text { Electrode }\end{aligned} \mid$ Solution $\mid$ Membrane $\mid$ Solution $\mid \begin{aligned} & \text { Reference Calomel } \\ & \text { Electrode }\end{aligned}$
Eled

The condition $\mathrm{I}=0$ is fulfilled by short circuiting electrodes and then taking measurements.

The formation of liquid membrane is indicated by lowering of membrane potential and it is clear from the membrane potential values, given in Table 1,2.

Since cellulose acetate is practically uncharged its selectively is considerably low. Permselectivity was estimated using the equation [13]

$$
P_{s}=\frac{\overline{t_{+}}-t_{+}}{t_{+}-\left(2 t_{+}-1\right) \overline{t_{+}}}
$$

The transport number on the basis of TMS theory may be given as [14], for 1:1 electrolyte i.e. for $\mathrm{NaCl}$ and $\mathrm{KCl}$.

$$
\overline{t_{+}}=\frac{E}{2 E_{\max }}+0.5
$$

Where the symbols have their usual meaning. A simplification of TMS theory gives:

$$
E=\frac{R T}{F}\left(2 \overline{t_{+}}-1\right) \ln \frac{a_{1}}{a_{2}}
$$

and if the membrane is ideally selective,

$$
E_{\max }=\frac{R T}{F} \ln \frac{a_{1}}{a_{2}}
$$

Permselectivity is related to fixed charge density as [15]

$$
\varnothing \bar{x}=\frac{2 \bar{c} P_{s}}{\sqrt{1-P_{s}^{2}}}
$$

Where $\overline{\mathrm{C}}$ is the mean concentration.

For $\mathrm{CaCl}_{2}$, which is 2:1 electrolyte, the membrane potential which is infact the liquid junction potential is given as [16]

$$
E_{L}=\left[1-\frac{3}{2} t_{+}\right] \frac{R T}{F} \ln \frac{a_{1}}{a_{2}}
$$

Where the activities are the geometric mean activities. For an ideally selective membrane this potential is given as

$$
E_{\max }=\frac{-R T}{2 F} \ln \frac{a_{1}}{a_{2}}
$$

Teorell-Meyer-Sievers theory gives the following expression for membrane potential for 2:1 electrolyte [17]

$$
E=\left[1-\frac{3}{2} \bar{t}_{+}\right] \frac{R T}{F} \ln \frac{a_{1}}{a_{2}}
$$

Solving Eqs (6) and (8) the transport number $\overline{\mathrm{t}}_{+}$, may be given as :

$$
\bar{t}_{+}=\frac{E}{E_{L}}\left[\bar{t}_{+}-\frac{2}{3}\right]+\frac{2}{3}
$$

\begin{tabular}{|c|c|c|c|c|c|c|}
\hline \multirow{2}{*}{$\begin{array}{l}\text { C } \\
\left(\mathrm{mol}-\mathrm{dm}^{-3}\right)\end{array}$} & \multirow{2}{*}{\multicolumn{2}{|c|}{$\begin{array}{l}\mathrm{C}_{1} \\
\left(\mathrm{~mol}-\mathrm{dm}^{-3}\right)\end{array}$}} & \multirow{2}{*}{\multicolumn{2}{|c|}{$\begin{array}{l}\mathrm{C}_{2} \\
\left(\mathrm{~mol}-\mathrm{dm}^{-3}\right)^{\mathrm{f} 2}\end{array}$}} & \multicolumn{2}{|l|}{$E(m V)$} \\
\hline & & & & & Without ergosterol & With ergosterol \\
\hline 0.075 & 0.1 & 0.5322 & 0.05 & 0.6402 & 14.5 & 13.6 \\
\hline 0.15 & 0.2 & 0.4828 & 0.1 & 0.5322 & 13.1 & 12.3 \\
\hline 0.30 & 0.4 & 0.2833 & 0.2 & 0.4828 & 12.8 & 11.4 \\
\hline 0.60 & 0.8 & 0.1680 & 0.4 & 0.2833 & 11.9 & 10.1 \\
\hline 0.75 & 1.0 & 0.1361 & 0.5 & 0.2441 & 7.5 & 6.4 \\
\hline
\end{tabular}

For calculating $\bar{t}_{+}$the experimentally measured values of membrane potential E, have been used.

In Table 3 the values of transport numbers for $\mathrm{CaCl}_{2}$ are given which are calculated using eqn. $9 . \mathrm{E}_{\mathrm{L}}$ and $\mathrm{E}_{\max }$ values, calculated by using eqs (6) and (7) are also recorded in this table.

\begin{tabular}{lllllll}
\hline $\begin{array}{l}C \\
\left(\mathrm{~mol}-\mathrm{dm}^{-3}\right)\end{array}$ & $\begin{array}{l}\mathrm{C}_{1} \\
\left(\mathrm{~mol}-\mathrm{dm}^{-3}\right)^{\mathrm{f} 1}\end{array}$ & $\mathrm{f} 2$ & $\begin{array}{l}\mathrm{C}_{2} \\
\left(\mathrm{~mol}-\mathrm{dm}^{-3}\right)\end{array}$ & $\begin{array}{l}\mathrm{E}(\mathrm{mV}) \\
\text { Without ergosterol }\end{array}$ \\
\hline 0.15 & 0.2 & 0.6949 & 0.7730 & 0.1 & 14.9 & 13.6 \\
0.30 & 0.4 & 0.5976 & 0.6949 & 0.2 & 12.3 & 12.5 \\
0.45 & 0.6 & 0.5263 & 0.6351 & 0.3 & 11.6 & 10.3 \\
0.60 & 0.8 & 0.4828 & 0.5976 & 0.4 & 10.3 & 9.7 \\
0.75 & 1.0 & 0.4430 & 0.5623 & 0.5 & 9.1
\end{tabular}

Table 1: Membrane potential data at different mean concentration of $\mathrm{NaCl}$ with and without ergosterol.

Table 2: Membrane potential data at different mean concentration of $\mathrm{CaCl} 2$ with and without ergosterol at $25^{\circ} \pm 0.1^{\circ} \mathrm{C}$. 


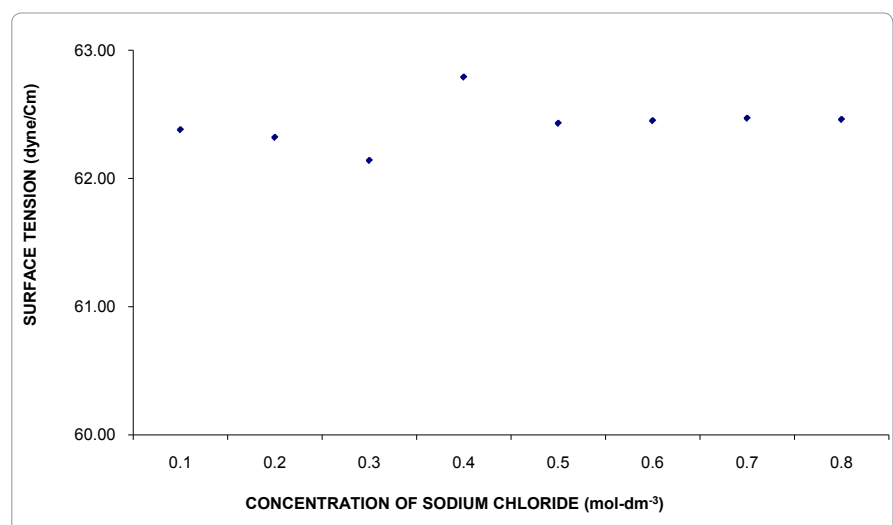

Figure 3: Variation of Surface Tension with Different Concentration of Sodium Chloride.

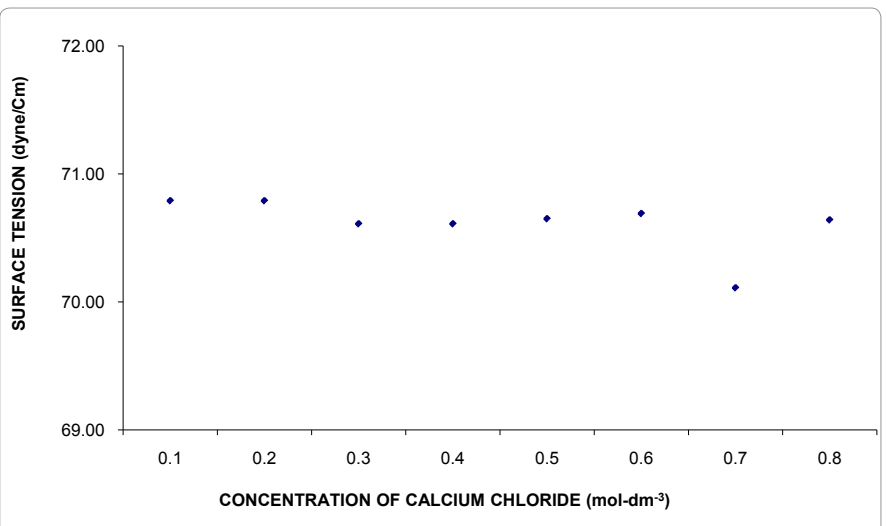

Figure 4: Variation of Surface Tension with Different Concentration of Calcium Chloride.

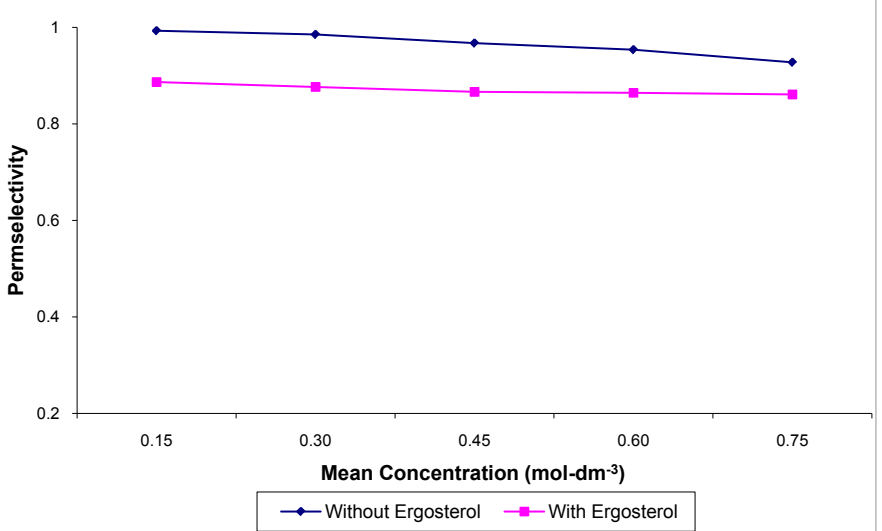

Figure 5: Variation of permselectivity with mean concentration for cellulose acetate sodium chloride system.

Activity coefficient values needed for the estimation of activity were calculated using the equation [18]

$\log \mathrm{f}=-\mathrm{AZ}_{+} \mathrm{Z}_{-} \sqrt{\mathrm{I}}$

Where $\mathrm{f}=$ activity coefficient of the electrolyte $\mathrm{Z}_{+}$and $\mathrm{Z}_{-}$are ionic charges of the cation and anion respectively and $\mathrm{A}$ is a constant.

In Table 3, the transport number values for calcium chloride system are given. The results show that cellulose acetate film exhibits change in selectivity i.e. at lower mean concentration, $\mathrm{E}$ is greater than $E_{L}$ even when cellulose acetate supports ergosterol liquid membrane, it indicates towards anion acceleration, but as the mean concentration increases, $E_{L}$ becomes greater than $E$ either with or without ergosterol liquid membrane. Thus at higher mean concentration cation is accelerated, since $t_{+}>t$ transport number is found to increase with increasing mean concentration.

In case of $\mathrm{NaCl}$, the transport number increases with decreasing $\mathrm{pH}$ values showing that the anion selectivity increases with lowering of $\mathrm{pH}$ however a decrease in transport number with increasing concentration indicates the decrease of selectivity of the film with increasing mean concentration.

For $\mathrm{NaCl}$, the permselectivity and fixed charge density, both increase with decreasing $\mathrm{pH}$ (Table 4) but a decrease in permselectivity and increase in fixed charge density with increasing mean concentration is observed in the case of sodium chloride (Figure $5,6)$ as well as potassium chloride systems. It is known that cellulose acetate undergoes swelling when kept in aqueous solutions and the swelling decreases with increase in concentration. The deswelling of the cellulose acetate membrane is likely to enhance openness of its matrix

\begin{tabular}{llll}
\hline $\begin{array}{l}\mathrm{C} \\
\left(\mathrm{mol}-\mathrm{dm}^{-3}\right)\end{array}$ & $\mathrm{t}_{+}$ & $\mathrm{t}_{+}$ \\
\cline { 2 - 3 } & Without ergosterol & With ergosterol & \\
\hline 0.075 & 0.0142 & 0.0251 & 0.4041 \\
0.15 & 0.1050 & 0.1392 & 0.3980 \\
0.30 & 0.4601 & 0.4830 & 0.3842 \\
0.60 & 0.4861 & 0.5060 & 0.3650 \\
0.75 & 0.4900 & 0.5162 & 0.3520 \\
\hline
\end{tabular}

Table 3: Transport number values at different mean concentration of $\mathrm{CaCl}_{2}$ derived using eqn. (9).

\begin{tabular}{lllll}
\hline $\mathrm{pH}$ & $\mathrm{P}_{\mathrm{s}}$ & \multicolumn{3}{c}{$\varphi \overline{\left.X_{(m o l ~ d m}{ }^{-3}\right)}$} \\
\cline { 2 - 5 } & Without ergosterol & With ergosterol & Without ergosterol & With ergosterol \\
\hline 6.5 & 0.4683 & 0.3879 & 0.3580 & 0.2525 \\
5.5 & 0.5572 & 0.4439 & 0.4458 & 0.2972 \\
4.5 & 0.6477 & 0.5339 & 0.5474 & 0.3788 \\
3.5 & 0.6806 & 0.5802 & 0.6223 & 0.4275 \\
2.5 & 0.7342 & 0.6532 & 0.6789 & 0.5177 \\
1.5 & 0.7499 & 0.7022 & 0.6803 & 0.5918 \\
\hline
\end{tabular}

Table 4: Permselectivity and fixed charge density values at different $\mathrm{pH}$ for $\mathrm{NaCl}$ $C=0.30, C_{1}=0.40, C_{2}=0.20\left(\mathrm{~mol} \mathrm{dm}^{-3}\right)$.

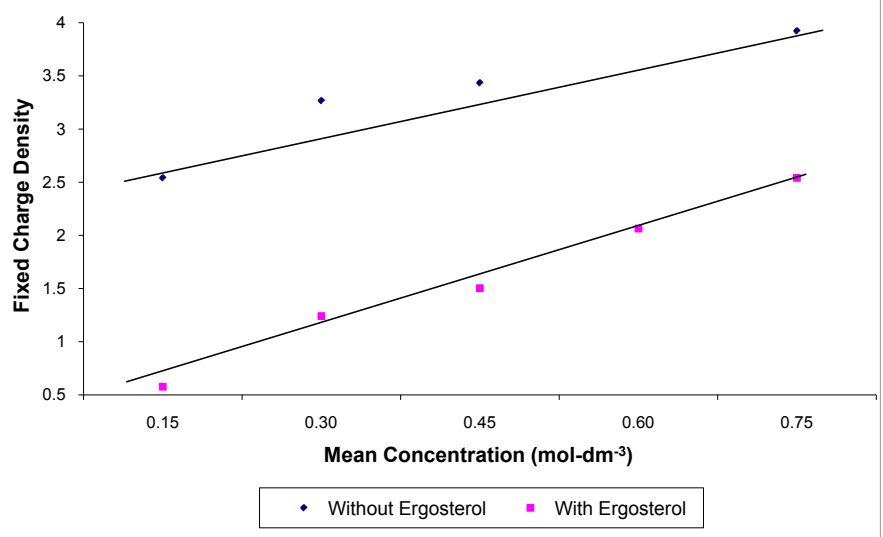

Figure 6: Variation of fixed charge density for cellulose acetate- sodium chloride system at different mean concentrations. 


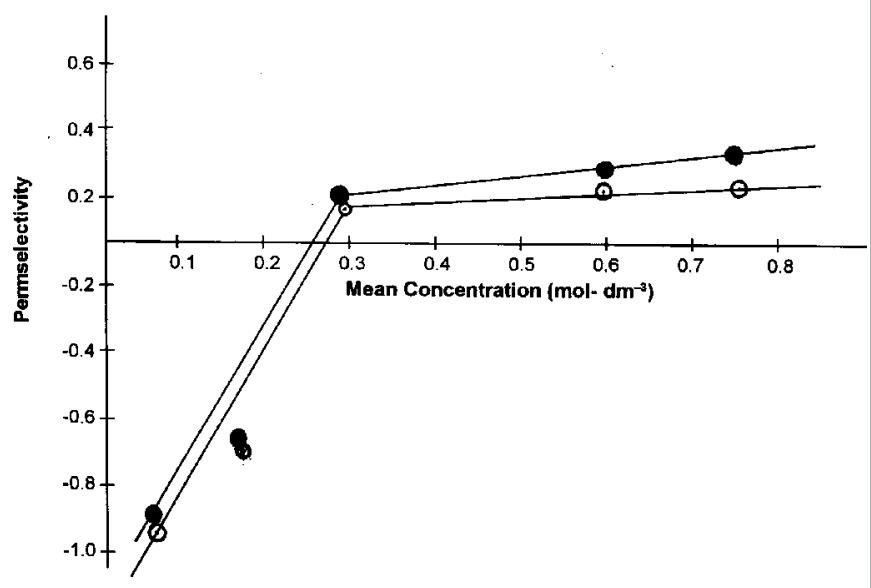

$\odot$ Without Ergosterol With Ergosterol

Figure 7: Variation of permselectivity with mean concentration for cellulose acetate-calcium chloride system.

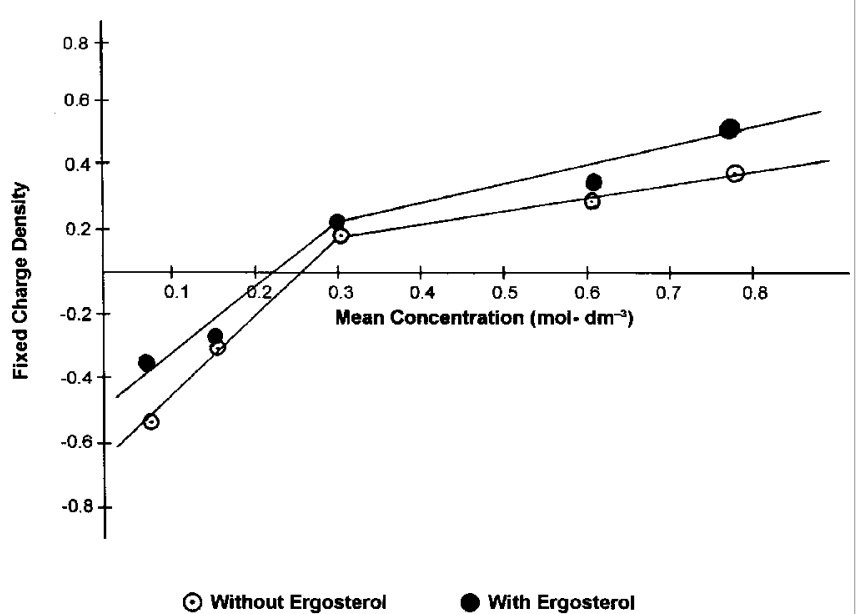

Figure 8: Variation of fixed charge density with mean concentration for cellulose acetate-calcium chloride system.

leading to reduction in permselectivity inspite of increased fixed charge density with concentrations of $\mathrm{NaCl}$.

For $\mathrm{CaCl}_{2}$ system, at lower mean concentration, the permselectivity values are negative and with increasing concentration the values become positive (Figure 7). These values indicate that the selectivity of the cellulose acetate membrane is changing from anion to cation. The same trend is obtained for fixed charge density (Figure 8). An increasing tendency of both the parameters ensures an increase in selectivity of cellulose acetate membrane. An increase in permselectivity and fixed charge density with increasing $\mathrm{pH}$ values justifies the increase in selectivity.

When a surfactant is added to a membrane, the transmission characteristics of membrane is modified due to formation of immobilized structure [19,20]. Surfactants are amphipathic compounds. They consist of both hydrophilic and hydrophobic portions in the same molecule. In the case of ergosterol, only -OH group is hydrophilic and the rest part is hydrophobic. When dispersed in aqueous solution at low concentration, the surfactant migrates towards any available hydrophobic interface and orients its hydrophobic segment towards the interface and its hydrophilic portion in the aqueous phase [21-23]. During studies, it has been found that immobilization of the surfactant depends on many factors like $\mathrm{pH}$, ionic strength, temperature and surfactant structure.

The values for various parameters in the case of ergosterol liquid membrane supported on cellulose acetate film are larger than those obtained earlier [24]. This may be attributed to the structural feature of ergosterol which contains three double bonds in its structure resulting in the presence of electron rich environment. It is also responsible for enhanced surface activity.

\section{Acknowledgement}

The author is thankful to the Head, Department of Chemistry, D.D.U. Gorakhpur University, Gorakhpur for providing laboratory facilities. Special thanks are given to Dr.M.L.Srivastava, Professor, Deptt. of Chemistry,D.D.U. Gorakhpur University, Gorakhpur.

\section{References}

1. Mohapatra PK, Manchanda VK (2003) Indian J Chem A 42: 2925-2938.

2. Reits EAJ, Neefjes JJ (2001) Nat Cell Biol 3: 145-147.

3. Kenworthy AK, Nichols BJ, Remmert CL, Hendrix GM (2004) Dynamics of putative raft-associated proteins at the cell surface. J Cell Biol 165: 735-746.

4. Gambin Y, Massiera G, Ramos L, Ligoure C, Urbach W (2005) Bounded step superdiffusion in an oriented hexagonal phase. Phys Rev Lett 94: 110602

5. Girard P, Pecreaux J, Lenoir G, Falson P, Rigaud JL, et al. (2004) A new method for the reconstitution of membrane proteins into giant unilamellar vesicles. Biophys J 87: 419-429.

6. Lee V, Petersen NO, Revington M, Dunn SD (2003) The lateral diffusion of selectively aggregated peptides in giant unilamellar vesicles. Biophys $\mathrm{J} 84$ $1756-1764$.

7. Srivastava ML, Shukla NK (2003) On the electrochemical characterization of ion-selective cellulose acetate membranes with and without stigmasterol liquid membranes. J Colloid Interface Sci 267: 132-135.

8. Singh K, Tiwari AK (1987) J Membrane Sci 3: 155-163.

9. Srivastava RC, Jakhar RPS (1981) J Phys Chem 85: 1457

10. Singh K, Tiwari AK (1987) J Colloid Interface Sci 116: 42

11. Gershfeld NL, Pagano RE (1972) Physical chemistry of lipid films at the airwater interface. 3. The condensing effect of cholesterol. A critical examination of mixed-film studies. J Phys Chem 76: 1244-1249.

12. Singh K, Tiwari AK, Rai JP (1985) Indian J Chem 24: 825-827.

13. Kobatke Y, Kamo N (1973) Pog Polym Sci Jpn 5: 257.

14. Lakshminarayanaiah N (1969) Transport Phenomena in Membranes, 199.

15. Singh K, Shabd R, Srivastava VN (1981) Indian J Chem 20: 391.

16. Glasstone S (1974) An Introduction to Electrochemistry 122.

17. Lakshminarayanaiah N (1976) Membrane Electrodes, Academic Press 64.

18. Singh K, Tiwari AK, Dwivedi CS (2002) Indian J Chem A 41: 921-927.

19. Singh K, Shahi VK (1991) J Memb Sci 59: 27.

20. Srivastava RC, Jakhar RPS (1982) J Phys Chem 86: 1441

21. Hiemenz PC (1986) Principles of colloid and surface chemistry (2 ${ }^{\text {nd }}$ Edn) Marcel Dekker Inc.

22. Hoeft CE, Zollars RL (1996) Adsorption of Single Anionic Surfactants on Hydrophobic Surfaces. J Colloid Interface Sci 177: 171-178.

23. Rosen MJ (1986) Surfactant and interfacial phenomena. Wiley 43.

24. Srivastava ML, Shukla NK (1991) Bull Chem Soc Jpn. 